\title{
Hong Kong evolution curriculum row
}

A debate over the teaching of intelligent design in schools is raging in the unlikely battleground of Hong Kong. A fiery topic in the United States, intelligent design - which holds that a designer has shaped life on Earth - has gone almost unnoticed in Asia.

The controversy is affecting all levels of education. In the latest episode, a dean of science at one of Hong Kong's premier universities backed out of a radio show earlier this month after finding he was being set up to debate with an advocate of intelligent design within his faculty.

Hong Kong is in the middle of reforming its school system, and the Education Bureau has issued a series of guidelines for all levels of education to go into effect in September 2009. Within the 126-page guidelines for teaching biology at the secondary level, the section on 'Genetics and Evolution' includes the sentence: "In addition to Darwin's theory, students are encouraged to explore other explanations for evolution and the origins of life, to help illustrate the dynamic nature of scientific knowledge." The guidelines were prepared by the Curriculum Development Council and the Hong Kong Examinations and Assessment Authority.

Early this month, in the South China Morning Post, several senior scientists including astronomer Sun Kwok, freshwater ecologist David Dudgeon and geologist Jason Ali, all of the University of Hong Kong, called for the

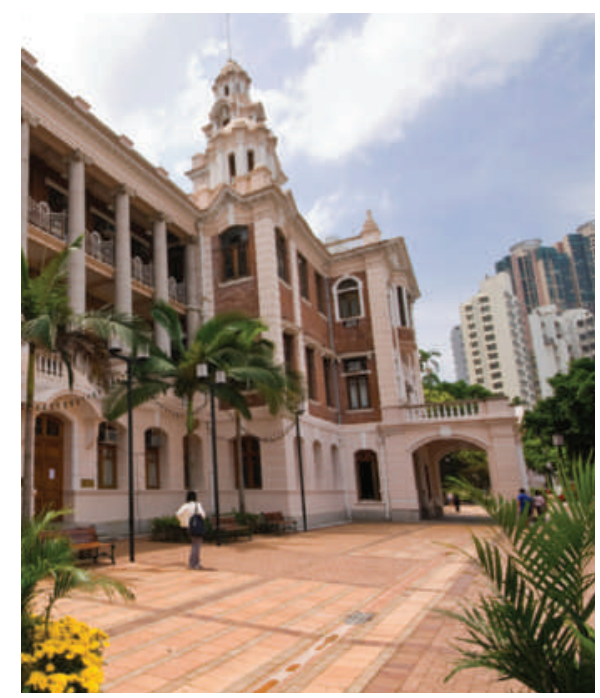

Science faculty will not teach intelligent design.

sentence to be omitted. In the same article, a spokeswoman for the Education Bureau defended the teaching of alternative explanations, because science cannot "provide a complete answer" about the emergence of life.

There has been heated debate in the Hong Kong media since. On 13 February, the radio series Backchat broadcast a programme on 'Creationism versus Evolution'. Kwok, dean of the science faculty at the university, backed out of the programme when he found it had been changed to a debate format at the last minute, noting that he is not a specialist in evolution and thus "cannot counter detailed arguments regarding evolution versus creation".

Chris Beling, a solid-state physicist and associate professor in the University of Hong Kong department of physics, debated with two other panellists and took the opportunity to "mildly criticize" the science faculty for refusing his request to continue a course on the origin of the Universe that included a section on intelligentdesign thinking. Instead, he has met in private with students to discuss intelligent design.

The depth of interest in intelligent design in Hong Kong is rare for Asia, says Chung-I $\mathrm{Wu}$, an evolutionary biologist at the University of Chicago and a visiting director at the Institute of Genomics in Beijing. "Each of us cardcarrying evolutionists has encountered issues of intelligent design in Taiwan or China," he says, "but the challenge is never serious enough to leave even a name or organization that we can recall." Beling says that the presence of many missionary schools in Hong Kong may explain why intelligent design has taken root there.

For now, Kwok and his university are unlikely to back down. "The position of the faculty of science of the University of Hong Kong is that pseudoscience subjects such as intelligent design, astrology and UFO studies have no place in our science curriculum," says Kwok.

David Cyranoski

\section{Satellite to monitor carbon sinks sinks}

A mishap shortly after launch led to the loss of the Orbiting Carbon Observatory (OCO), a NASA environmental monitoring satellite, on 24 February. The satellite crashed into the ocean off Antarctica.

"It's a major setback," says Paul Palmer, a climate scientist at the University of Edinburgh, UK, who is part of the OCO science team. It will be particularly devastating for the tight-knit group of scientists and engineers who have devoted much of the past decade to the project. "These guys have sweated OCO for seven or eight years," he says.

OCO, which cost US\$273 million, was designed to measure carbon dioxide levels at various depths in the atmosphere with high enough precision to allow the sources and sinks of the gas to be assessed. It would have provided researchers with a comparatively high-resolution global picture of how carbon dioxide is absorbed by oceans, forests and other components of the Earth system.

The satellite was launched aboard a Taurus XL rocket at 4:55 a.m. local time from Vandenberg Air Force Base in California. Shortly after launch, controllers announced that the protective clamshell 'fairing' that surrounded the satellite had failed to separate properly.

The Taurus was built by Orbital Sciences Corporation of Dulles, Virginia; the company was also the main contractor on the spacecraft itself. This was the eighth launch of a Taurus rocket and the second failure. An investigating board was being set up as Nature went to press. The next payload booked for launch on a Taurus is another NASA satellite, Glory, which will study clouds and aerosols. It will not now be launched until OCO's loss is understood.

OCO was one of two carbon dioxidemonitoring satellites to launch this year. In late January, the Japanese Aerospace Exploration Agency launched the Greenhouse Gases Observing Satellite (GOSAT), which will monitor levels of methane, water vapour and carbon dioxide. That satellite seems to be functioning normally.

The two satellites would have been complementary to each other. Whereas GOSAT provides high spectral resolution of gases in the atmosphere, OCO would have provided detailed spatial resolution of carbon dioxide. In addition, the two satellites would have allowed scientists to check their data against one another. "Having two satellites was going to make life a lot easier," says Palmer.

Geoff Brumfiel 